\title{
Experimental Study on Laser Surface Texturing for Friction Coefficient Enhancement
}

\author{
Joerg SCHILLE ${ }^{* 1}$, Frank ULLMANN ${ }^{* 1}$, Lutz SCHNEIDER ${ }^{* 1}$, Matthias GRAEFENSTEINER ${ }^{* 2}$, Saskia SCHIEFER ${ }^{* 3}$, \\ Marco GERLACH ${ }^{* 3}$, Erhardt LEIDICH ${ }^{* 2}$, and Horst EXNER ${ }^{* 1}$ \\ ${ }^{*}$ Laserinstitut Hochschule Mittweida, Technikumplatz 17, 09648 Mittweida, Germany \\ ${ }^{* 2}$ Technische Universität Chemnitz, Department of Engineering Design, \\ Reichenhainer Str. 40, 09126 Chemnitz, Germany \\ ${ }^{*}$ Technische Universität Chemnitz, Institute of Production Measuring Technology \\ and Quality Assurance, Reichenhainer Str. 40, 09126 Chemnitz, Germany \\ schille@hs-mittweida.de
}

\begin{abstract}
Laser surface texturing of alloy steel $42 \mathrm{CrMo} 4+Q T$ (AISI 4140) was studied in order to significantly increase the friction coefficient of tribological systems. Two different surface topologies were investigated to functionalize the contact surface, such as dimple-shaped micro structures and deep welding dots. The dependencies of the laser processing parameters on the characteristics of these micro-scaled surface structures were evaluated. The coefficient of friction $\mu$, the static coefficient for dimple-shaped and kinetic for dot textures respectively, was determined in experimental torsion tests. Dimple-shaped micro structures were processed by using q-switched near-infrared laser pulses. The dimple diameter, wall height, and wall hardness were analyzed depending on both pulse energy and laser spot size. The maximum static coefficient of friction of dimple-shaped specimen was measured to be $\mu=0.53$, tested against fine grinded steel surfaces. This is almost twice the friction coefficient of the non-laser processed fine grinded reference contact surface which was determined of $\mu=0.3$. In a second approach, singular deep welding dots were fabricated by using high-power continuous wave laser radiation emitted by a single mode fiber laser. The geometric dimensions of these lenticular dots were studied depending on irradiated laser power and laser exposure time. Torsion testing of deep welding dot patterned surfaces indicated steadily increasing slipping curves with a maximum kinetic coefficient of friction of $\mu=0.82$ as obtained with the largest investigated torsion angle of $3^{\circ}$.
\end{abstract}

DOI: $10.2961 /$ jlmn.2015.03.0002

Keywords: friction, coefficient of friction, laser surface texturing, dimple-shaped, micro structure, deep welding dot

\section{Introduction}

Laser surface texturing (LST) has attracted great attention in tribology because of its promising potential to improve the frictional performance of tribological systems in terms of efficiency, load capacity, wear resistance, and lifetime. Most of the studies conducted so far in this research field have been focused on friction reduction, among others demonstrated in [1-6]. Therein micro-dimpled laser textures were identified as most effective to decrease the friction torque of mechanical components. These dimples usually function as micro-hydrodynamic bearings, micro reservoirs for lubricant retention or micro-traps for wear particles of sliding systems applicable, for example, in seals, piston rings, and thrust bearings.

However, only minor research has been done with the aim to increase the friction coefficient. In [7] it is recently reported that the static coefficient of friction of frictional engaged connections (cam, press fittings) can be increased by laser fabricated molten and re-solidified bulged micro structures. In this study, a near-infrared q-switched laser system was used to produce lines of overlapping pulses in order to roughening the mating surfaces. In another study, the effect of pulse energy and number of pulses was examined with the aim to fabricate high frictional stainless steel surfaces [8]. As a general trend it was reported that higher pulse overlap resulted in increased friction coefficients, but no direct correlation between each other was found. As a disadvantage, long processing times were being considered as limitation of the presented technologies for industrial applications. This is mainly due to the fact that highly overlapping laser pulses are necessarily required to produce the laser texture.

In this work, laser surface texturing of alloy steel $42 \mathrm{CrMo} 4+Q T$ (AISI 4140) was studied in order to significantly increase the friction coefficient. Two different surface topologies were investigated to functionalize the contact surface, isolated dimple-shaped micro structures produced by near-infrared q-switched laser pulses, and deep welding dots achieved by single mode continuous wave laser irradiations. Fabrication of dimple-shaped structures using single pulse laser irradiations with large spatial distance between each other, however, enables faster processing speeds, compared to high pulse overlap processing as reported in the literature. This seems to be beneficial for prospective industrial applications of the technology.

The dependencies of the laser processing parameters on the characteristics of the micro-scaled surface structures were evaluated using micrographs recorded by scanning electron microscope (SEM) and topography measurements.

Adequate laser textures were produced on ring-shaped standardized specimen and tested against non-laser processed fine grinded counterparts by using a friction test bench. Finally, the coefficients of friction obtained in these measurements were correlated to the surface topographies and their interdependencies have been discussed. 


\section{Experimental details}

\subsection{Laser texturing procedure}

Laser surface texturing was studied with the aim to significantly increase the friction behaviour of tribological contact surfaces. The specimens used in this study were standardized cylindrical test bodies made of alloy steel $42 \mathrm{CrMo4}+Q T$ (AISI 4140). On top of these bodies, there was a fine grinded planar ring-shaped friction surface with an average roughness of $R_{Z}<3.6 \mu \mathrm{m}$. These friction contact areas were laser textured with two different surface topologies. The first texture, dimple-shaped micro structures, was produced by isolated pulse irradiations using a qswitched laser. While the other, singular deep welding dots, was fabricated using high-power continuous wave laser radiation emitted from a single mode fiber laser. Laser texturing was performed by utilizing galvanometer scanner systems in order to focus and deflect the laser beams across the friction surface. The most important laser and processing parameters used in this work are summarized in Table 1 .

Table 1: Laser parameters.

\begin{tabular}{|c|c|c|}
\hline Parameter & $\begin{array}{c}\text { q-switched } \\
\text { laser }\end{array}$ & $\begin{array}{c}\text { single mode cw } \\
\text { fiber laser }\end{array}$ \\
\hline Wavelength $[\mathrm{nm}]$ & 1064 & 1070 \\
\hline Laser power $[\mathrm{W}]$ & 45 & 3,000 \\
\hline Max. pulse energy $[\mathrm{mJ}]$ & 9 & - \\
\hline $\begin{array}{c}\text { Pulse duration / }[\mu \mathrm{s}] \\
\text { Exposure time }\end{array}$ & 0.11 & $500 \ldots 2,000$ \\
\hline Focal length $[\mathrm{mm}]$ & 100 & 230 \\
\hline Focus diameter $[\mu \mathrm{m}]$ & 70 & 21 \\
\hline \multicolumn{2}{|c}{} \\
\hline
\end{tabular}

\subsection{Coefficient of friction testing}

The coefficient of friction $\mu$ for laser textured surfaces was measured using a friction test bench as shown in Figure 1. In this setup, the laser surface textured test specimens were pressed against fine grinded counterparts of similar shape using different nominal surface pressures of $30 \mathrm{MPa}, 100 \mathrm{MPa}$, and $300 \mathrm{MPa}$, respectively.

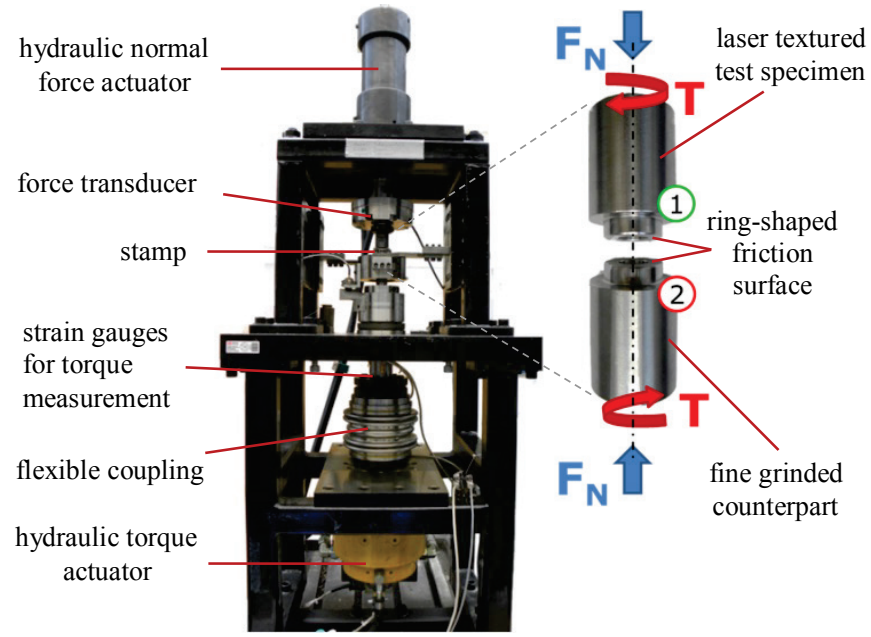

Figure 1: Test bench (left) and test specimen setup (right) as used to determine the coefficient of friction of laser textured surfaces, the ring-shaped friction surface on top of the test bodies is indicated.
To achieve these contact pressures, pre-load forces of $15.9 \mathrm{kN}, 53.0 \mathrm{kN}$ and $159.0 \mathrm{kN}$ were set with the hydraulic normal force actuator. The nominal surface contact area at the interface between the laser textured specimen and the counterpart was determined by the inner and outer ring diameter of $d_{i}=15.0 \mathrm{~mm}$ and $d_{o}=30.0 \mathrm{~mm}$. This yielded an effective friction diameter of $D_{m}=23.33 \mathrm{~mm}$, calculated according to equation (1).

$$
D_{m}=\frac{2}{3} \cdot \frac{d_{o}^{3}-d_{i}^{3}}{d_{o}^{2}-d_{i}^{2}}
$$

In the friction test, the twisting angle was increased continuously with a speed of $0.5^{\circ}$ per second until the twisting angle of $3.0^{\circ}$ was reached. The nominal preload force $F_{N}$, the torque $T$ and the twisting angle $\varphi$ were recorded continuously. The resulting slipping curves are shown for example in Figure 2, obtained by plotting the torque versus the twisting angle. In the plot, three individual dimple-shaped laser textured surfaces were tested against fine grinded counterparts.

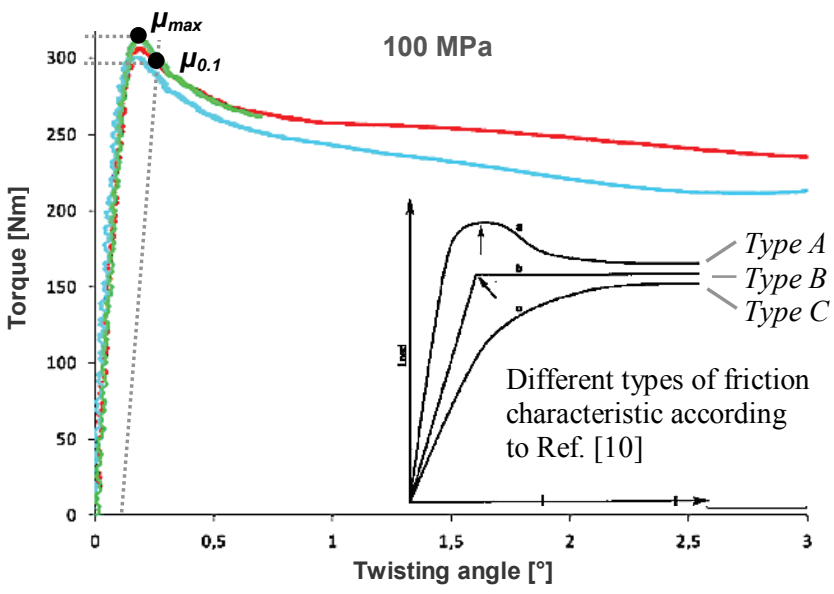

Figure 2: Slipping curves obtained in torsion testing of three dimple-shaped laser textured friction surfaces using $100 \mathrm{MPa}$ surface pressures; the method used to determine the maximum coefficient of friction and the friction coefficient at $0.1^{\circ}$ twist-

ing angle is shown, a schematic taken from [10] to indicate three types of friction characteristics is presented.

The coefficients of friction were derived from the slipping curves by using an evaluation method introduced in [9]. According to this method, two distinct friction coefficients $\mu_{0.1}$ and $\mu_{\max }$ were analyzed. The static friction coefficient $\mu_{0.1}$ was obtained from the torque maximum for twisting angles in the range $\varphi \leq 0.1^{\circ}$. The friction coefficient $\mu_{\max }$, by contrast, was derived from the frictional torque maximum that was obtained in the twisting angle measuring range up to $3.0^{\circ}$. Using these torque values and by taking into account the pre-load force $F_{N}$ and effective friction diameter $D_{m}$, the coefficient of friction was calculated according to equation (2).

$$
\mu=\frac{2 \cdot T}{F_{N} \cdot D_{m}}
$$

Three different types of friction are classified in this work depending on the characteristic of the recorded slipping curve. The friction types are defined on the basis of typical load-slip response presented in [10] as follows: 
Type A: steep rising slipping curve with pronounced torque maximum before slipping is recorded, the torque decreases with further curve progression,

Type B: steep rise of the slipping curve at the beginning to a maximum, followed by stable or slightly increasing curve progression,

Type $C$ : flat slope of the slipping curve and steadily increasing friction with increasing torsion angle.

\subsection{Geometric characterization}

The coefficient of friction highly depends on the form and orientation of the friction surface in contact with the counterparts. For this reason, form, waviness, and roughness of the specimens used in friction measurements were analysed in order to ensure repeatable geometrical properties of the contact surfaces and thus friction measurement conditions. For this, a 3D surface evaluation method including a high-precision form measuring instrument (MFU 100, Mahr) was applied [11]. Therefore, a roughness stylus was used for holistic geometric characterization of the friction surface (Figure 3 a), a form stylus was used to analyse nominal form and orientation of the contact surface (Figure 3 b), respectively.
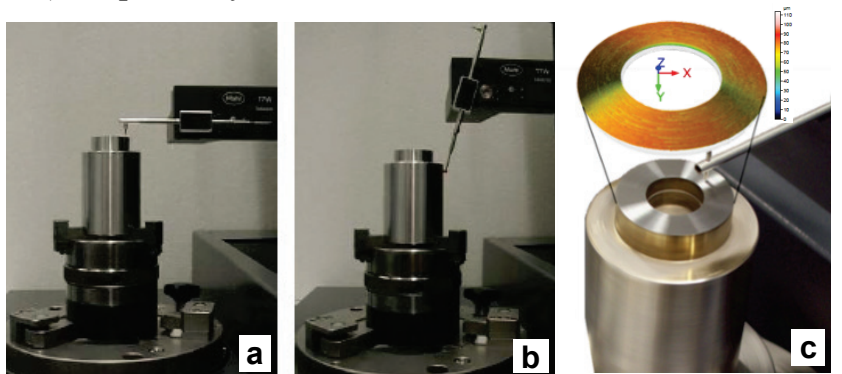

Figure 3 a: Holistic geometric characterization of a test specimen by using the roughness stylus; b) measurement of form and orientation of the contact surface by using a form stylus;

c) $3 \mathrm{D}$ profile extracted from the friction surface measurement.

From the 3D measurement data, the entire geometry of the laser textured friction surface was extracted and available for characterization (Figure $3 \mathrm{c}$ ). As first approximation, and proved by several tests, it was proposed that the laser textured surface and the surface of the counterpart interact to a depth maximum of either $20 \%$ for dimpleshaped structures or $10 \%$ for deep welding dots of this material ratio that was measured from the Areal Material Ratio Curve (Abbott curve) [11, 12]. The depth value, measured down from the maximum point of this curve, which corresponds to the specific material ratio (of either $10 \%$ or $20 \%$ ), defines the evaluation height $c$. In the following, this evaluation height was used to separate the laser produced structures and the substrate basic surface structure (basic roughness) in terms of their functionality.

Figure 4 shows schematically the procedure used in this work to determine the friction-relevant surface parameters, such as number of islands $N I$, mean surface of the islands $M S I$, and mean volume of the material for a specific evaluation height $M V M$. By cutting the measured surface as given in Figure $4 \mathrm{a}$ at the evaluation height $c$, the number of islands $N I=3$ was obtained (Figure $4 \mathrm{~b}$ ). In the Figures $4 \mathrm{c}$ and $4 \mathrm{~d}$, the mean surface of islands $\left.\left(M S I=A_{1}+A_{2}+A_{3}\right) / 3\right)$ and the total material volume $\left(V=V_{1}+V_{2}+V_{3}\right)$ above the evaluation height $c$ are indicated. The mean value of the volume of the material for a specific evaluation height $M V M$, however, was calculated from the functional volume parameters of the Abbott curve, as defined in [13]. a)

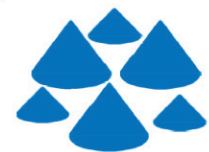

b)
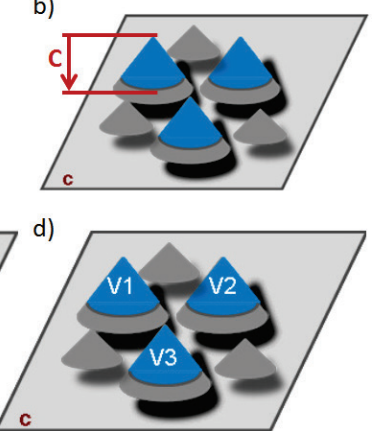

Figure 4: Procedure used to determine friction-relevant surface parameters; from the measured surface (a) the number of islands (b), mean surface of the islands (c) and volume of the material above a specific evaluation height (d) were derived by using the evaluation height $c$.

In addition to the 3D measurements, microstructural characterization and cross sections views of the laser textured surface were studied before and after the friction tests using SEM and optical microscopy micrographs.

\section{Results and discussion}

\subsection{Dimple-shaped micro structures for static friction} coefficient enhancement

A laser textured alloy steel surface covered with separated dimple-shaped micro structures is exemplarily presented in Figure 5. In this SEM micrograph, the distance between the dimples to each other is in the range of $280 \mu \mathrm{m}$, which is little larger than the dimple size of $160 \times 250 \mu \mathrm{m}^{2}$ in width and length. The magnified micrograph shown in the upper right hand corner of Figure 5 gives a closer view to an individual dimple structure. In this image, formation of the wall structure at the outer dimple area but also material bulging in the center region can be observed. These heightening originated as a result of material melting and re-solidification potentially caused by laser induced plasma melt dynamics.

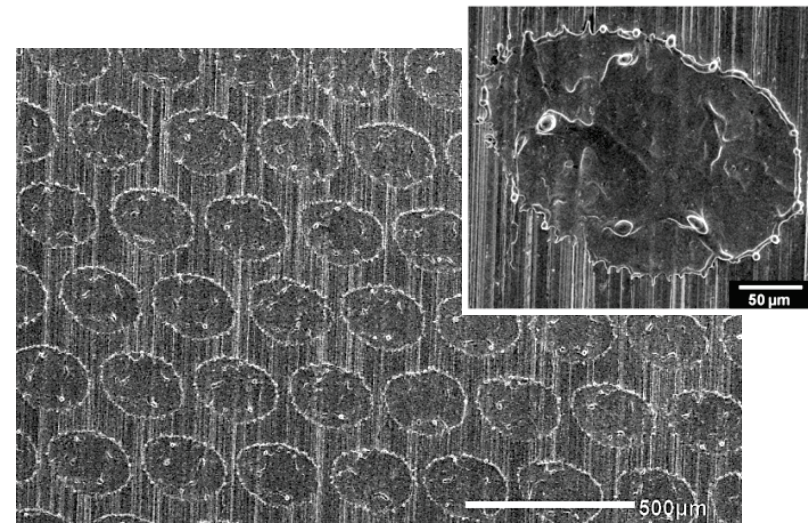

Figure 5: SEM micrograph of a dimple-shaped laser textured friction surface, a magnified image gives a closer view to the wall formations originated at the outer area of the dimple due to re-solidification of molten material.

Figure 6 a presents a cut-out of 3D measurement data as extracted from the dimple-shaped laser textured friction surface given above in Figure 5. From this surface profile, 
the friction-relevant geometrical parameters of the laser texture were evaluated by cutting the profile at the evaluation height $c=17.2 \mu \mathrm{m}$, determined at $20 \%$ material ratio. The resulting height profile is shown in Figure $6 \mathrm{~b}$.

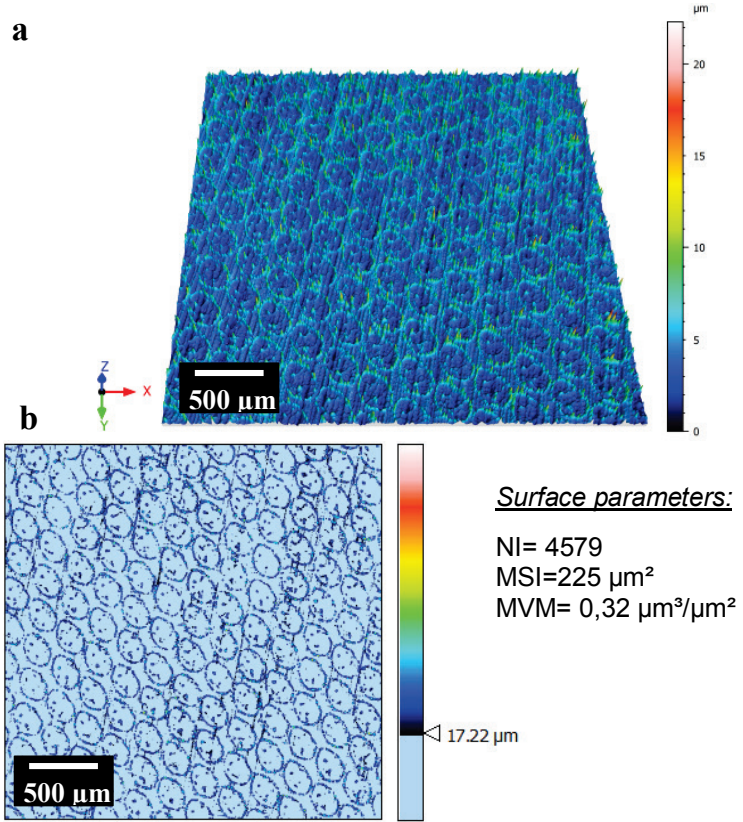

Figure 6 a: 3D measurement data extracted from the dimpleshaped friction surface given above in Figure 5 ; b) frictionrelevant surface obtained by cutting the laser textured surface at the evaluation height $c=17.2 \mu \mathrm{m}$ and $20 \%$ material ratio.

The static coefficient of friction of dimple-shaped laser textured surfaces was studied depending on the size and shape of the dimple structures. For this, the wall height of the outer dimple region and the dimple diameter were varied by the applied laser parameters. The influence of the distance between the processing plane (used to laser texture the friction surface) relative to the focal plane on the wall height and dimple diameter is presented in Figure 7. In addition, the energy of the laser pulses irradiated to the friction surface was varied. The diameter of the dimples made in focal plane position is about $120 \mu \mathrm{m}$ which is larger than the focus spot diameter of the laser beam $(70 \mu \mathrm{m})$. This is potentially affected by the impinging high-energy laser pulses of $470 \mathrm{~J} / \mathrm{cm}^{2}$ fluence those might cause steel

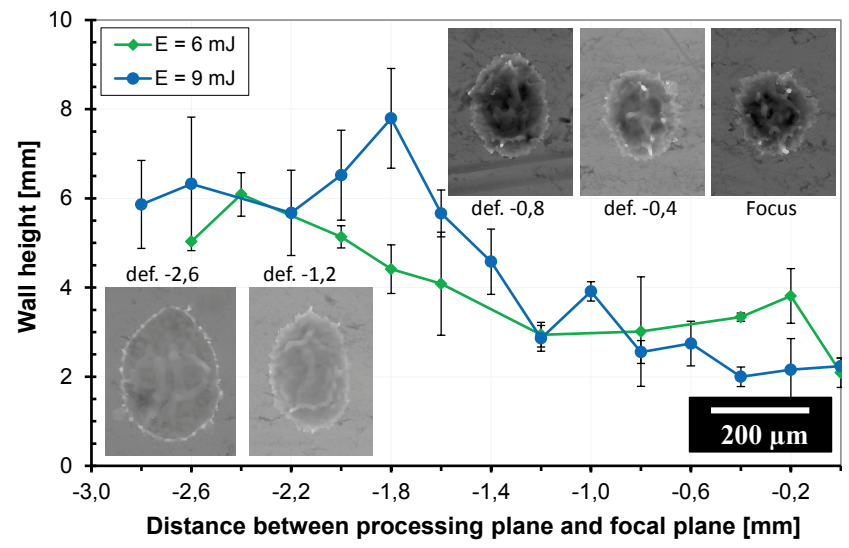

Figure 7: Wall height of dimple-shaped micro structures versus distance between processing plane and focal plane; the pulse energy was varied between $6 \mathrm{~mJ}$ and $9 \mathrm{~mJ}$; SEM micrographs of the dimples processed with $9 \mathrm{~mJ}$ pulse energy are shown (def. denotes defocused processing position). melting in greater regions than the focus spot area. Further it can be assumed that the dimple size depends on the pulse duration which was $110 \mathrm{~ns}$ in this study. Thus, using these long pulses, the molten/ablated region has been potentially extended as a result of heat diffusion out of the focal area.

As indicated in Figure 7, dimple diameter and wall height increased with either higher pulse energy or longer distance between processing plane and focal plane or both The increase of the dimple size with longer distance between laser irradiated friction surface and focal plane (denoted in Figure 7 as def.) is mainly induced by defocusing the divergent laser beam. As a result, expanding the laser spot caused larger irradiation areas and thus larger diameter of the molten wall structure. With further defocusing the spatial beam profile changed to elliptical beam shape.

Using the single pulse processing regime, the maximum wall height of about $8 \mu \mathrm{m}$ was obtained by irradiating pulses with the highest available energy of $9 \mathrm{~mJ}$. In this case, the friction surface to be textured was placed $1.8 \mathrm{~mm}$ underneath the focal plane. For these processing conditions it can be supposed that the ratio between laser energy (to melt the material) and intensity (induces plasma pressure) is reasonably effective to form high dimple walls. As already mentioned above, the dimple walls will potentially arise as a result of plasma melt dynamics.

For the shorter distances between processing plane and focal plane, however, pulses of higher intensity irradiated the friction surface due to the smaller laser spot sizes. Therefore it can be suggested that material ablation/evaporation was dominant and thus less amount of melting was produced. This was probably the main cause for the lower height of the dimple walls those have been formed in less defocused laser texturing, as can be seen in Figure 7. For laser pulses irradiated to the substrate placed farther away than $1.8 \mathrm{~mm}$ from the focal plane, by contrast, the intensity seems to be too low to form the wall structure. This is mainly due to the larger spot size of the laser beam irradiated at this larger defocused substrate position.

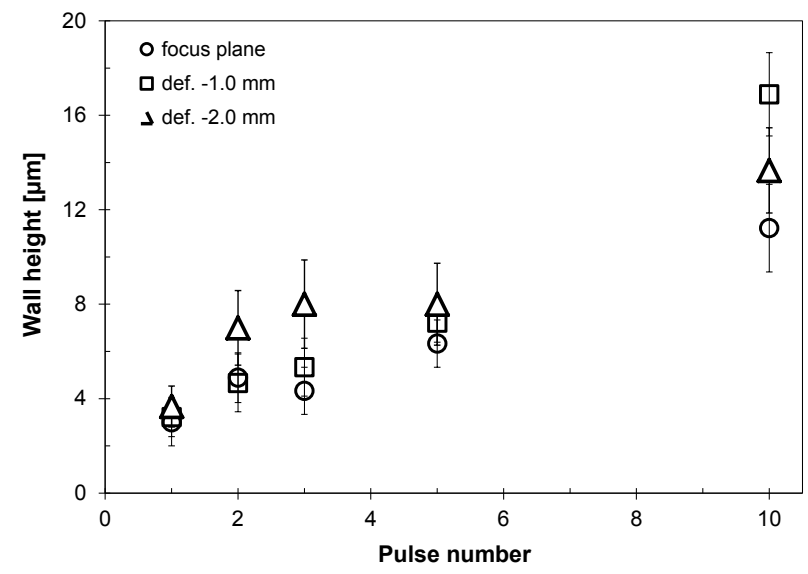

Figure 8: Wall height versus pulse number obtained for different positions of the processing plane relative to the focal plane; the pulse energy was $9 \mathrm{~mJ}$.

To further increase the height of the dimple walls, multiple numbers of laser pulses were irradiated at the same place. Figure 8 plots the wall height versus number of irradiated pulses; the position of the processing plane relative to the focal plane was varied. It can be seen that the wall height increased steadily with higher pulse number. A max- 
imum height of $16 \mu \mathrm{m}$ was achieved with 10 pulses of $9 \mathrm{~mJ}$ energies and $1.0 \mathrm{~mm}$ defocused processing plane.

The characteristic geometry of the dimple-shaped micro structures obtained with multiple laser irradiations are presented in Figure 9. Pulses of $9 \mathrm{~mJ}$ energy were irradiated to the friction surface which was placed $2 \mathrm{~mm}$ underneath the focal plane. Significant changes of the wall shape can be seen with increasing pulse number. While crown-shaped walls featured with high number of islands originated with 1 or 2 pulses, closed ring walls were obtained with higher pulse numbers.

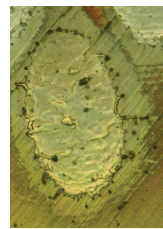

1

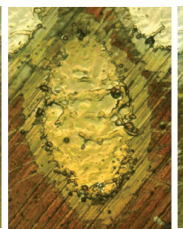

2

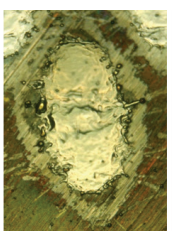

3

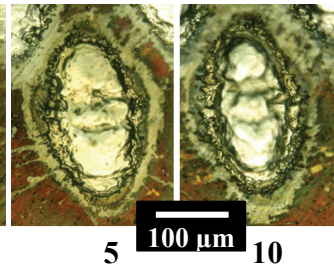

Pulse number

Figure 9: Characteristic geometry of dimple-shaped micro structures depending on the irradiated pulse number;

$2 \mathrm{~mm}$ defocused laser pulses of $9 \mathrm{~mJ}$ were irradiated.

The hardness of the molten and re-solidified walls formed at the outer dimple region was measured by using nano indentation technique. The imprint of a nano indenter on the wall structure can be seen in Figure 10 a (red encircled). Figure $10 \mathrm{~b}$ plots the Normal displacement vs. Normal Force - curve as measured for the substrate as well as the walls produced with different processing parameters.

In the Figures $10 \mathrm{c}$ and $10 \mathrm{~d}$, the hardness measuring points placed on the wall regions are indicated by red circles. In addition, a different appearance of the dimple/wall formation can be seen. In Figure $10 \mathrm{c}$, single laser pulses of higher intensity, obtained by $1.0 \mathrm{~mm}$ defocusing of $9 \mathrm{~mJ}$ pulses, were irradiated to the friction surface, forming a melt splattered outer dimple region. In Figure $10 \mathrm{~d}$, by contrast, molten and re-solidified wall formations were obtained by irradiating a $2.0 \mathrm{~mm}$ defocused laser pulse of $9 \mathrm{~mJ}$ energy. The hardness of these dimple walls was measured independently from the processing parameters in the range of $784 \pm 257 \mathrm{HV}$. This is almost twice the hardness of the substrate of $398 \pm 52 \mathrm{HV}$.

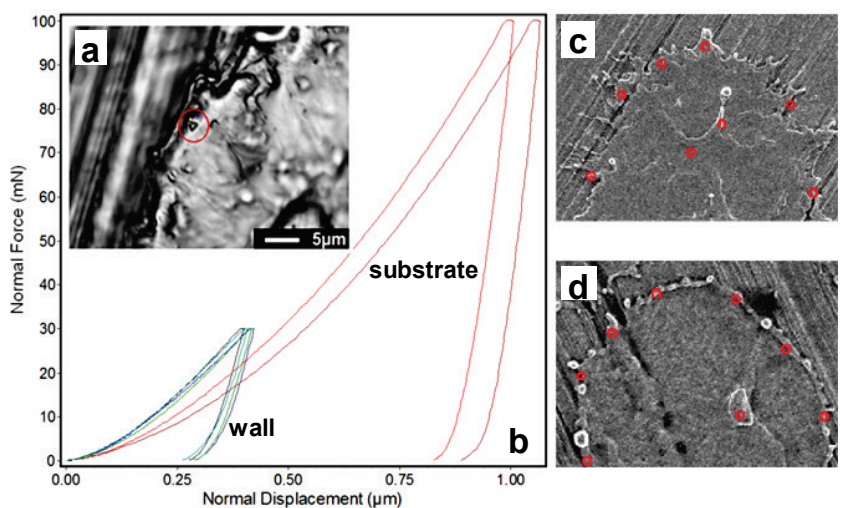

Figure 10: Hardness measurement on dimple walls using nano indentation technique, a) imprint of a nano indenter on a dimple wall (red encircled), b) measurement curves, c) dimple-shaped micro structure achieved with a $1.0 \mathrm{~mm}$ defocused laser pulse of $9 \mathrm{~mJ}$, d) dimple-shaped micro structure achieved with a $2.0 \mathrm{~mm}$ defocused laser pulse of $9 \mathrm{~mJ}$.
For friction tests, three distinct dimple-shaped laser textures of varying geometrical characteristics were selected from the results achieved in the fundamental investigations presented above. The processing parameters applied to texture the friction surfaces as well as the resulting geometrical texture parameters are summarized in Table 2.

The smallest wall height of about $4 \mu \mathrm{m}$ was measured for Texture \#1. This is in the range of the mean surface roughness of the used specimen and is likely cause of the high scatter of the number of islands. The highest number of islands was found for Texture \#2 while the ring-shaped Texture \#3 is featured by the highest and most voluminous dimple-shaped wall structures achieved in this study.

A closer view to the analyzed laser textured friction surfaces is given in Table 3. The presented SEM micrographs reveal a clear difference between the geometrical shape of the dimples produced with single laser pulses (Texture \#1 and \#2) in comparison to the dimples processed with 10 pulses (Texture \#3). In addition, the static coefficients of friction as measured against non-laser processed fine grinded alloy steel counterparts are presented.

Table 2: Processing conditions and geometrical texture parameters of the laser textures studied in static coefficient of friction measurements, $N I$ is the number of islands, $M S I$ is the mean surface of the islands and $M V M$ is the mean volume of the material for a specific evaluation height.

\begin{tabular}{|c|c|c|c|c|}
\hline \multirow{4}{*}{ 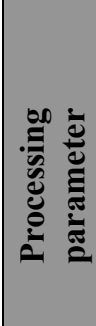 } & & Texture \#1 & Texture \#2 & Texture \#3 \\
\hline & $\begin{array}{c}\text { Pulse } \\
\text { energy }\end{array}$ & $9 \mathrm{~mJ}$ & $9 \mathrm{~mJ}$ & $9 \mathrm{~mJ}$ \\
\hline & $\begin{array}{c}\text { Processing } \\
\text { plane } \\
\text { position }\end{array}$ & $\begin{array}{c}1 \mathrm{~mm} \\
\text { defocused }\end{array}$ & $\begin{array}{c}2 \mathrm{~mm} \\
\text { defocused }\end{array}$ & $\begin{array}{c}2 \mathrm{~mm} \\
\text { defocused }\end{array}$ \\
\hline & $\begin{array}{c}\text { Pulse } \\
\text { number }\end{array}$ & 1 & 1 & 10 \\
\hline \multirow{5}{*}{ 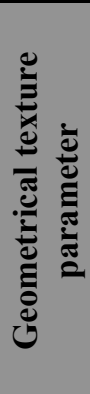 } & $\begin{array}{l}\text { Dimple size } \\
\text { (elliptical) }\end{array}$ & $\begin{array}{c}200 \mu \mathrm{m} x \\
130 \mu \mathrm{m}\end{array}$ & $\begin{array}{c}250 \mu \mathrm{m} x \\
160 \mu \mathrm{m}\end{array}$ & $\begin{array}{c}250 \mu \mathrm{m} x \\
160 \mu \mathrm{m}\end{array}$ \\
\hline & $N I$ & $2570 \pm 2525$ & $4594 \pm 645$ & $1787 \pm 261$ \\
\hline & MSI & $\begin{array}{c}485 \pm 267 \\
\mu \mathrm{m}^{2}\end{array}$ & $\begin{array}{c}221 \pm 42 \\
\mu \mathrm{m}^{2}\end{array}$ & $\begin{array}{c}710 \pm 123 \\
\mu \mathrm{m}^{2}\end{array}$ \\
\hline & $M V M$ & $\begin{array}{c}0.12 \pm 0.02 \\
\mu \mathrm{m}^{3} / \mu \mathrm{m}^{2}\end{array}$ & $\begin{array}{c}0.31 \pm 0.01 \\
\mu \mathrm{m}^{3} / \mu \mathrm{m}^{2}\end{array}$ & $\begin{array}{c}0.55 \pm 0.03 \\
\mu \mathrm{m}^{3} / \mu \mathrm{m}^{2}\end{array}$ \\
\hline & $\begin{array}{c}\text { Dimple } \\
\text { wall height }\end{array}$ & $4 \mu \mathrm{m}$ & $7 \mu \mathrm{m}$ & $12 \mu \mathrm{m}$ \\
\hline
\end{tabular}

With reference to the static coefficient of friction of fine grinded friction surfaces, as measured to be $\mu_{\text {ref }}=0.3$ (indicated in Table 3 by a dotted line), a significant friction increase was detected for laser textured friction surfaces. By using the classification of the friction characteristic introduced in Figure 2, Texture \#1 and \#2 showing steep rising slipping curves with pronounced maximum correlate to type $A$. Texture \#3, by contrast, matches better to type $B$ due to a steep rise of the slipping curve at the beginning, followed by slightly increase with further curve progression. From this, it can be supposed that the friction behavior will be substantially determined by the texture characteristic of the friction surface.

Friction measurements carried out on dimple-shaped surface textures yielded the highest static coefficient of friction of $\mu=0.53$, measured on Texture \#2 at the twisting 
angle of $0.1^{\circ}$ and a surface pressure of $30 \mathrm{MPa}$, respectively. At this low contact pressure, the dimples interact with the counter body surface. Friction tests using higher surface pressures, by contrast, yielded slightly lower static coefficients of friction, which were similar to the friction coefficient of the non-laser processed reference surface $\left(\mu_{\text {ref }}=0.3\right)$. This behavior is potentially caused by the small height of the dimple walls $(7 \mu \mathrm{m})$ compared to micro topology and roughness of the fine grounded substrate $\left(R_{Z}<3.6 \mu \mathrm{m}\right)$. At higher nominal contact pressure, the dimple wall structures could not penetrate deeper into the counter body surface and, as a result, the frictional effect is dominated by interaction between the fine grounded substrate surface and the counter body surface.

Table 3: SEM micrographs show the texture of the analyzed friction surfaces and the static coefficient of friction as measured against non-textured fine grounded counterparts with different contact pressures (30 MPa, $100 \mathrm{MPa}, 300 \mathrm{MPa})$; the measured friction coefficient of non-textured friction surfaces $\mu_{r e f}=0.3$ is indicated by dotted lines.

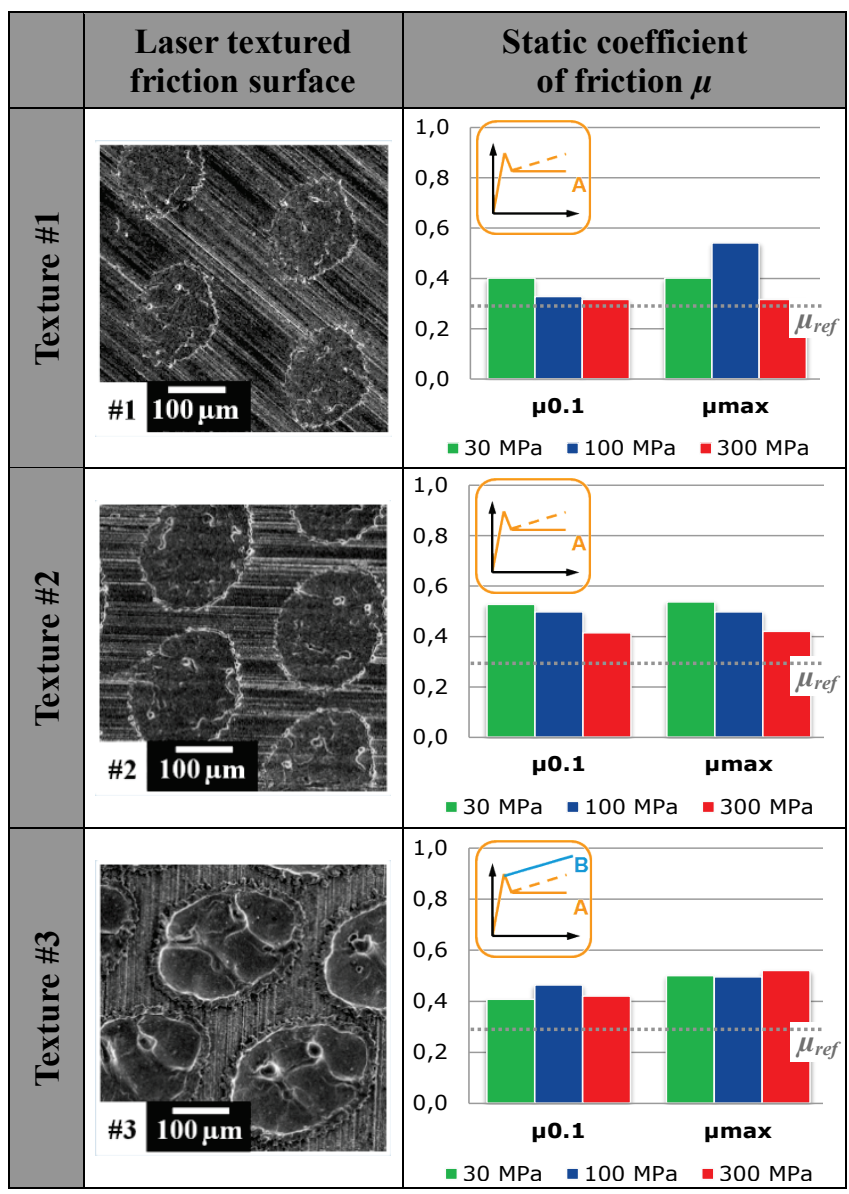

Considerably lower friction coefficients were measured for Texture \#1 with a maximum of $\mu=0.4$ (with exception of $\mu_{\max }$ at $100 \mathrm{MPa}$ ). This might be caused by the lower wall height and/or reduced number of islands of Texture \#1 compared to Texture \#2. However, a clear correlation between the static coefficient of friction and geometric dimple texture parameters cannot be identified.

From these finding it can be deduced that the value of static coefficient of friction cannot be predicted only from the knowledge of the geometric texture parameters. Thus, to holistically analyze the friction behavior of dimple- shaped laser textures not only geometric surface parameters but also adhesion has to be taken into account. The latter has not been fully cleared up so far and further work is needed.

\subsection{Deep penetration welding dot textured surfaces for kinetic friction coefficient enhancement}

In a second approach, deep penetration welding dots as exemplarily shown in Figure 11 were investigated with regard to their feasibility for friction coefficient increase. The micrograph shown in Figure $11 \mathrm{~b}$ presents a cross section of such a lenticular material bulge. Therein a deep penetration welding root can be observed, indicating deep penetration welding effects as potential dot formation mechanism. Welding roots as the result of keyhole formation in deep melting pool are characteristic for deep penetration laser welding. Pores and voids can be seen in their central and deeper region.

The characteristic properties of deep penetration welding dots, produced by using the continuous wave single mode fibre laser, depended greatly on the laser processing conditions. In this work, the dependencies of the dot diameter, height, and hardness on the laser power were studied in the range between $300 \mathrm{~W}$ and $900 \mathrm{~W}$. Three distinct laser exposure times of $500 \mu \mathrm{s}, 1,000 \mu \mathrm{s}$, and $2,000 \mu \mathrm{s}$ were investigated. The friction surfaces to be processed were placed in focal plane position where the laser beam was focused to a spot of $21 \mu \mathrm{m}$ diameter, obtained by using the $230 \mathrm{~mm}$-theta objective.

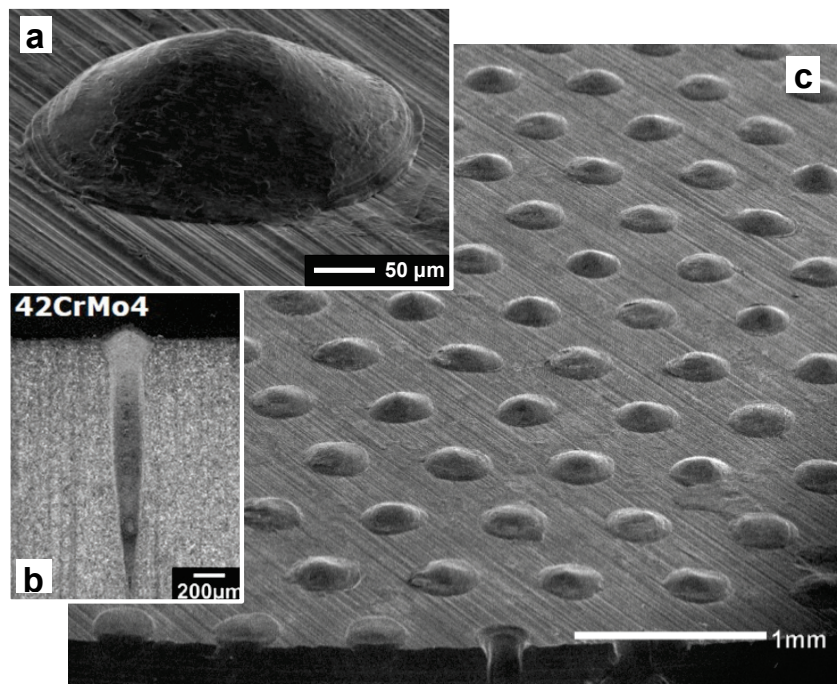

Figure 11: SEM micrographs of deep penetration welding dots produced in alloy steel, a) magnified view to a single deep penetration welding dot, b) cross section view of a welding dot, c) laser textured friction surface.

Figure 12 a plots the diameter of deep penetration welding dots as a function of laser power. It can be seen that the diameter varied in the range between $220 \mu \mathrm{m}$ and $310 \mu \mathrm{m}$. In general, the diameter increased with higher laser power and longer exposure times. Figure $12 \mathrm{~b}$ presents the height of the produced dots which was measured by using an optical digital microscopy. In the investigated parameter range the maximum dot height was $73 \mu \mathrm{m}$, obtained with either $800 \mathrm{~W}$ laser power and $500 \mu$ s exposure time or $500 \mathrm{~W}$ and $1,000 \mu \mathrm{s}$, respectively. For these parameter sets, however, a 
great scatter of the height values of more than $40 \%$ was detected that will cause irregular friction surface conditions. This, in turn, will potentially adversely affect the performance of the tribological systems.

Regular friction surfaces covered with deep penetration welding dots of similar geometry to the previous ones but considerably smaller standard deviation (height: $70 \mu \mathrm{m} \pm$ $7 \%$; diameter $312 \mu \mathrm{m} \pm 3 \%$ ) were produced with $500 \mathrm{~W}$ laser power and 2,000 $\mu$ s exposure time. The aspect ratio of these dots was 0.22 , obtained by dividing the dot height by the dot diameter.
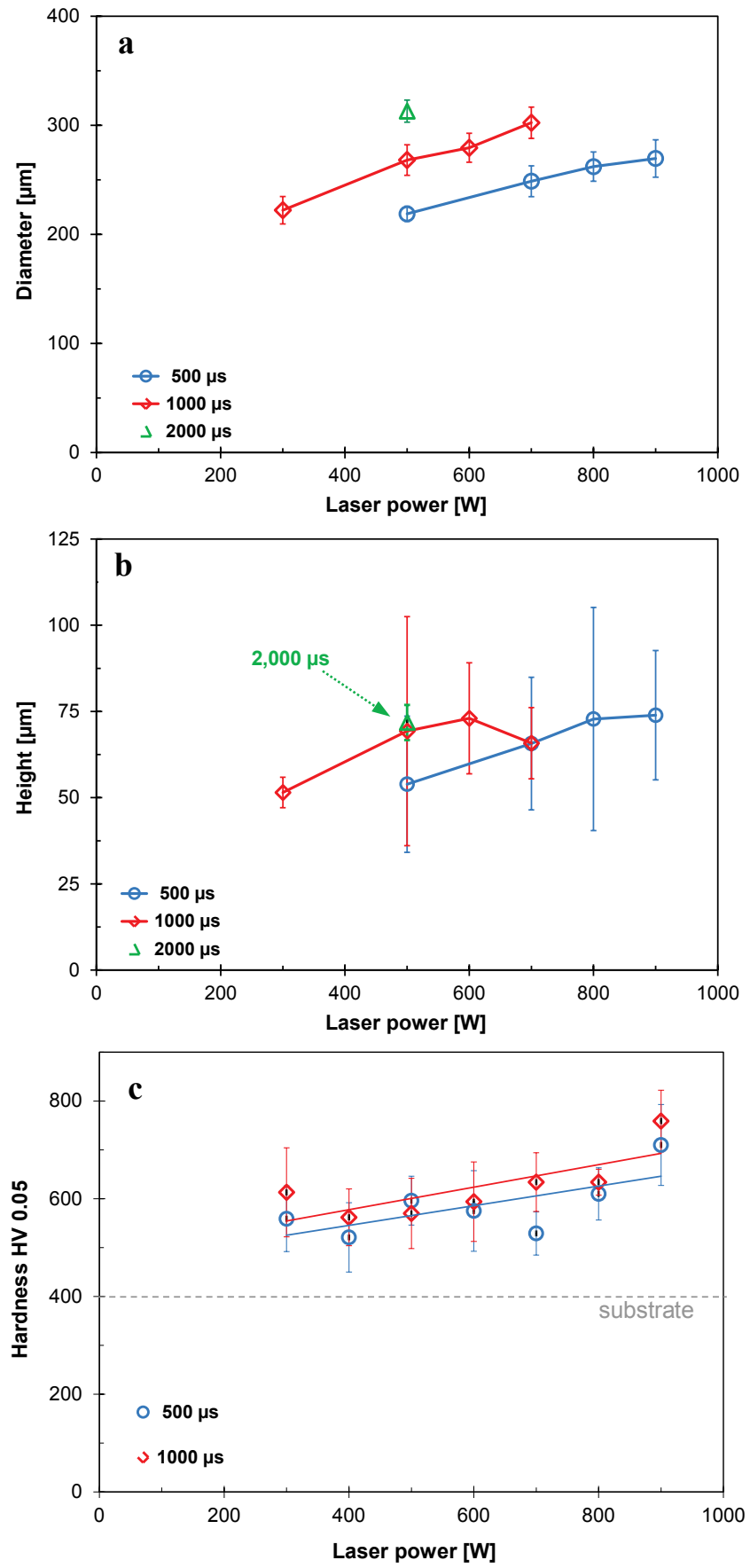

Figure 12: Influence of laser power and exposure time on a) diameter, b) height, and c) Vickers hardness of deep penetration welding dots as produced by single mode continuous was fiber laser irradiations.

The hardness of the deep penetration welding dots was evaluated by Vickers hardness measurements. In Figure $12 \mathrm{c}$ it can be seen that hardness increased with higher laser power and longer laser exposure from about $550 \mathrm{HV} 0.05$ to $800 \mathrm{HV} 0.05$. This is considerably higher than the hardness of the non-laser processed alloy steel substrate which was measured of about 400 HV0.05.

Figure 13 a presents the $3 \mathrm{D}$ profile of a typical deep penetration welding dot laser textured friction surface where the evaluation height $c$ was $50.2 \mu \mathrm{m}$. The individual dots were produced with $500 \mathrm{~W}$ laser power and 2,000 $\mu \mathrm{s}$ exposure time; the dot density as the dot number per area was 3.2 dots $/ \mathrm{mm}^{2}$. 3D-analysis of a series of four of this friction surface yields an averaged total dot number of $1655 \pm 103$ per friction surface. This quantity is little lower than the theoretical dot number of 1696 dots per friction surface. Imperfect dot formation at the edges of the specimens was suggested as main reason for the lower experimentally achieved dot value (see Figure $11 \mathrm{c}$ ).

In addition, a little number of skips (averaged to be 10 per friction surface) and height artefacts (about 5 per friction surface) have been observed on the laser textured friction surface which further affected the experimental dot number. For example, magnified images of these skips and height artefacts are shown in Figure 13 a.

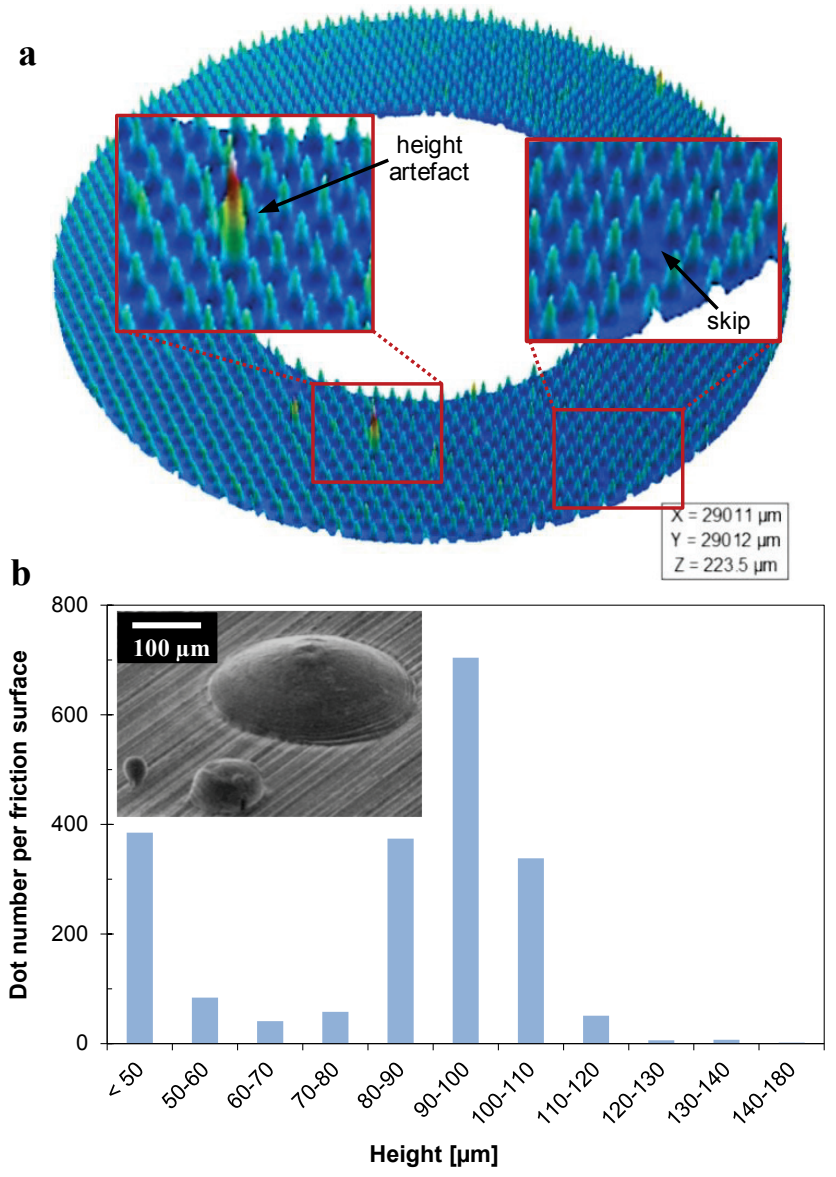

Figure 13 a: 3D profile of a deep penetration welding dot laser textured friction surface where the evaluation height $c$ was $50.2 \mu \mathrm{m}, \mathbf{b})$ distribution of the dot heights evaluated for a laser textured specimen surface.

Figure $13 \mathrm{~b}$ presents the distribution of the individual dot height values depending on their absolute height level. It can be seen that about $90 \%$ of the dots were produced with a height in the range between $80 \mu \mathrm{m}$ and $110 \mu \mathrm{m}$. The increased number of dots having a height smaller than 
$50 \mu \mathrm{m}$ is most likely due to irregular melt structures those originated next to the deep penetration dots, as shown in the SEM micrograph presented in Figure $13 \mathrm{~b}$. This height is identical to the evaluation height $c$ which was determined of $50.2 \mu \mathrm{m}$ at $20 \%$ material ratio from the Areal Material Ratio Curve. It is worth mentioning that the dot heights achieved in 3D profile analysis have found to be $20 \mu \mathrm{m}$ larger than the dot heights presented in Figure 12, which were obtained using the digital optical microscope.

The aspect ratio of the deep penetration welding dots can be varied by moving the laser beam across the sample surface in a circular fashion. For the studied laser power ranging between $300 \mathrm{~W}$ and $1,000 \mathrm{~W}$ it was found that the dot diameter enlarged with greater rotation radius and/or higher laser energy input caused by lower scan speeds.

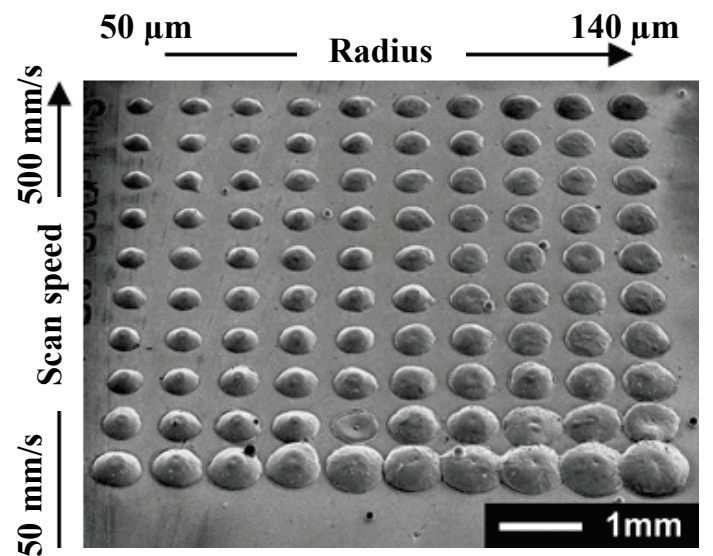

Figure 14: SEM micrograph of deep penetration welding dots produced with a single mode NIR continuous wave fiber

laser beam of $750 \mathrm{~W}$ laser powers; the scan speed and the rotation radius were varied in order to vary the aspect ratio.

For example, Figure 14 presents welding dots produced with $750 \mathrm{~W}$ laser power; the scan speed and the rotation radius were varied in the range from $50 \mathrm{~mm} / \mathrm{s}$ to $500 \mathrm{~mm} / \mathrm{s}$ and $50 \mu \mathrm{m}$ to $140 \mu \mathrm{m}$, respectively. Thereby the maximum dot height of $120 \mu \mathrm{m}$ was obtained with $50 \mathrm{~mm} / \mathrm{s}$ scan speed and $70 \mu \mathrm{m}$ radius. The maximum aspect ratio of these dots was 0.30 that is larger than the aspect ratio mentioned above using stationary irradiation conditions of 0.21 .

Table 4: Laser processing conditions and geometrical parameters of the deep welding dot textures studied in coefficient of friction measurements.

\begin{tabular}{|c|c|c|c|c|}
\hline \multirow{4}{*}{ 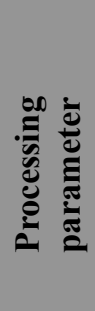 } & & Texture \#1 & Texture \#2 & Texture \#3 \\
\hline & $\begin{array}{l}\text { Laser } \\
\text { power }\end{array}$ & $500 \mathrm{~W}$ & $500 \mathrm{~W}$ & $350 \mathrm{~W}$ \\
\hline & $\begin{array}{c}\text { Exposure } \\
\text { time }\end{array}$ & $2,000 \mu \mathrm{s}$ & $2,000 \mu \mathrm{s}$ & n.a. \\
\hline & $\begin{array}{c}\text { Radius / } \\
\text { speed }\end{array}$ & 0 / n.a. & 0 / n.a. & $\begin{array}{c}30 \mu \mathrm{m} / \\
700 \mathrm{~mm} / \mathrm{s}\end{array}$ \\
\hline \multirow{4}{*}{ 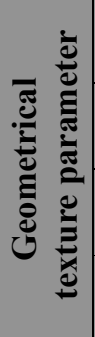 } & $\begin{array}{c}\text { Dot } \\
\text { diameter }\end{array}$ & $330 \mu \mathrm{m}$ & $330 \mu \mathrm{m}$ & $274 \mu \mathrm{m}$ \\
\hline & $\begin{array}{c}\text { Dot } \\
\text { height }\end{array}$ & $70 \mu \mathrm{m}$ & $70 \mu \mathrm{m}$ & $70 \mu \mathrm{m}$ \\
\hline & $\begin{array}{l}\text { Aspect } \\
\text { ratio }\end{array}$ & 0.21 & 0.21 & 0.26 \\
\hline & $\begin{array}{c}\text { Dot } \\
\text { density }\end{array}$ & $3.2 \mathrm{dots} / \mathrm{mm}^{2}$ & $2.0 \mathrm{dots} / \mathrm{mm}^{2}$ & 3.2 dots $/ \mathrm{mm}^{2}$ \\
\hline
\end{tabular}

In the friction measurements, three different deep penetration welding dot surface textures were tested against non-laser processed fine grinded counterparts. The laser processing conditions as well as geometry parameters of the studied dot structures are presented in Table 4.

SEM micrographs of the laser textured surface and the respective kinetic coefficient of friction values obtained are presented in Table 5. The slipping curves for all three investigated deep welding dot textures indicate a slipping characteristic according to type $C$. This means that the torque increased continuously during testing of deep penetration welding dot textured friction surfaces, and the quoted maximum friction value is not for static but for kinetic friction. The geometric dot parameters seem to have less influence on static friction at $0.1^{\circ}$ twisting angle because for all three variants almost similar friction coefficients were determined, ranging between $\mu_{0.1}=0.35 \ldots 0.42$. The coefficient of friction increased with larger twisting angle to values in the range between $\mu_{\max }=0.6 \ldots 0.7$. As already mentioned for static friction, also for kinetic friction no significant influence of the geometrical texture parameters was found. This was with exception of Texture \#1 where the maximum coefficient of friction was $\mu_{\max }=0.82$, tested at $100 \mathrm{MPa}$ contact pressure. In comparison to the dimple shaped laser textures discussed in the previous section, the friction coefficients $\mu_{0.1}$ of the deep welding dot textured surfaces were determined of similar value.

Table 5: Laser processing conditions and geometrical parameters of deep welding dot textures studied in coefficient of friction measurements.

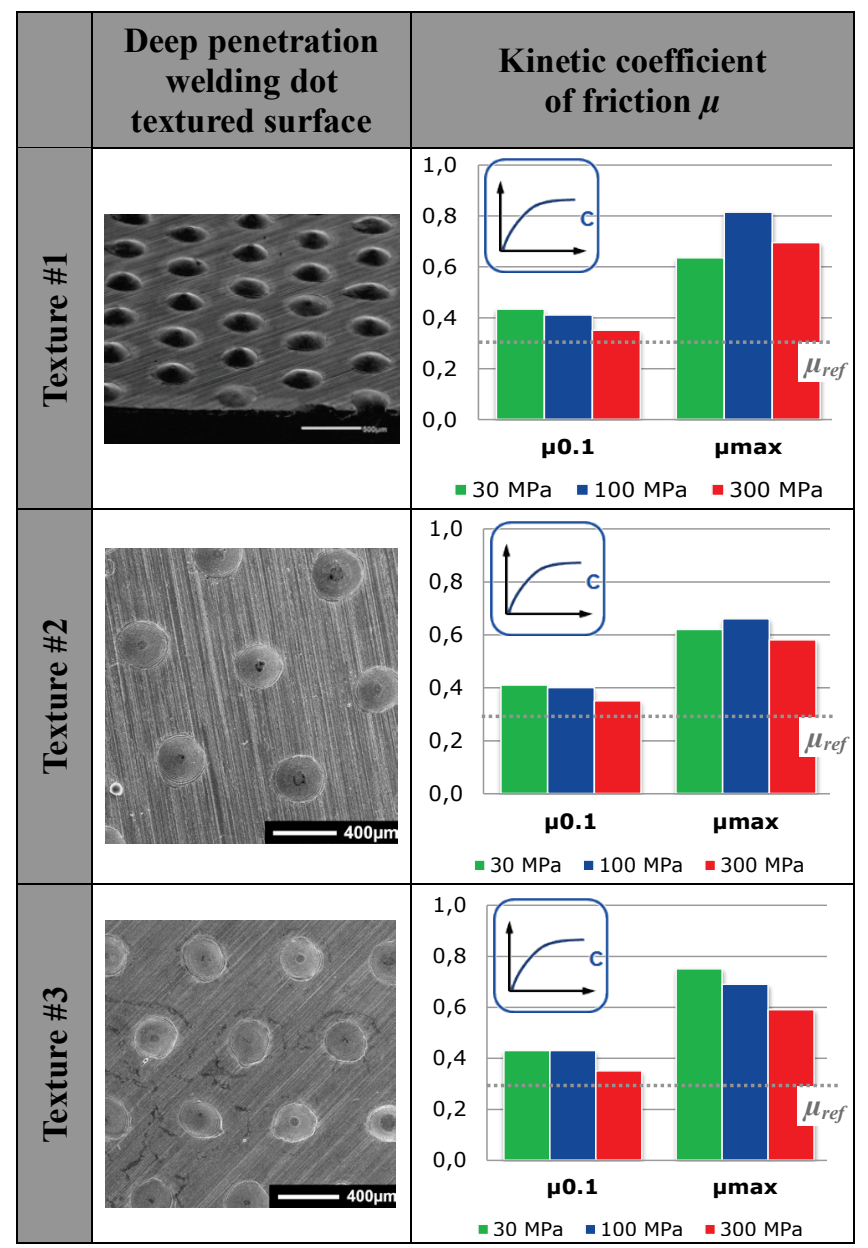




\section{Conclusion}

Laser surface texturing of alloy steel $42 \mathrm{CrMo} 4+Q T$ (AISI 4140) was studied with the aim to increase their coefficient of friction. For two different surface textures the dependencies of the processing conditions (laser power, focus position, exposure time) on their geometrical characteristic were investigated.

The coefficient of friction $\mu$ of the laser textured friction surfaces was determined in experimental torsion tests using a friction test bench. In this assembly, the laser textured specimens were pressed against non-laser processed counterparts of similar shape using different surface pressures of $30 \mathrm{MPa}, 100 \mathrm{MPa}$ and $300 \mathrm{MPa}$, respectively.

The first laser texture, a dimple-shaped micro structure, is characterized by molten and re-solidified micro-walls appearing at the outer area of the laser irradiation zone. These substructures were potentially formed by plasma and melt dynamics. To achieve wall heights up to $8 \mu \mathrm{m}$, focused Nd:YAG laser pulses with a maximum energy of $9 \mathrm{~mJ}$ were irradiated. The dimple diameter, wall height, and wall hardness were studied depending on both the pulse energy and the size of the laser spot at the sample surface. By using this technology, the maximum static friction coefficient has nearly doubled to be $\mu=0.53$, compared to nonlaser processed reference surfaces where the friction coefficient was $\mu_{r e f}=0.3$. The frictional behaviour of dimpleshaped friction surfaces correlated to type A, showing steep rise of the slipping curve with a pronounced torque maximum.

As a second laser texture, singular deep welding dots were fabricated by using high-power continuous wave laser radiation emitted by a single mode fiber laser. The geometric dimensions of these lenticular dots were studied depending on irradiated laser power and laser exposure time. A maximum height of $120 \mu \mathrm{m}$ and a width of $400 \mu \mathrm{m}$ were obtained and, moreover, the hardness increased with higher laser power to a maximum of $800 \mathrm{HV}$. The frictional characteristic of these structures correlate with type $C$. The maximal kinetic friction coefficient obtained in the measurement range was $\mu=0.82$. No significant influence of the dot density and the aspect ratio was found.

\section{Acknowledgements}

The presented results have been conducted in the course of the subproject "TP-V: Laser textured surfaces with high static friction" (AiF No. 17.228 BR) within the AiF/DFG joint CLUSTER promotion plan "GECKO - Design and determination of characteristic parameters for frictionally engaged optimized surfaces", funded via AiF by the German Federal Ministry of Economics and Technology (BMWi).

\section{References}

[1] I. Etsion, G. Halperin, V. Brizmer, and Y. Kligerman: Experimental investigation of laser surface textured parallel thrust bearings, Tribology Letters, 17, (2004) p.295.

[2] I. Etsion: State of the Art in Laser Surface Texturing, Transactions of the ASME, 127, (2005) p.248.

[3] H. Liu, R. Niu, and Y. Meng: The Effect of Laser Texturing of Steel Surfaces on Film Lubriction Based on Stribeck Curves, Proceedings of CIST 2008 \& ITS-IFToMM 2008 Beijing, China, (2008) p.685.

[4] D. Xiong, H. Wu, Z. Huang, J. Dai, and R. Tyagi: Tribological Properties of Laser Surface Texturing and Molybdenizing Duplex-Treated Ni-Base Alloy, Tribology Transactions, 53, (2010) p.195.

[5] T. Hu and L. Hu: The study of tribological properties of laser-textured surface of 2024 aluminium alloy under boundary lubrication, Lubrication Science, 24, (2012) p.84

[6] F. P. Mezzapesa, M. Scaraggi, G. Carbone, D. Sorgente, A. Ancona, and P. M. Lugarà: Varying the geometry of laser surface microtexturing to enhance the frictional behavior of lubricated steel surfaces, Physics Procedia, 41, (2013) p.677.

[7] G. Flores and A. Wiens: Mit dem Laserstrahl die Haftreibung erhöhen (written in German), Werkstatt und Betrieb - München, 146, (2013) p.102.

[8] A. Dunn, J. V. Carstensen, K. L. Wlodarczyk, E. B. Hansen, J. Gabzdyl, P. M. Harrison, J. D. Shephard, and D. P. Hand: Nanosecond laser texturing for high friction applications, Optics and Lasers in Engineering, 62, (2014) p.9.

[9] E. Leidich and S. Schuller: Haftreibung, Abschlussbericht (written in German), FVV, Heft Nr. 906, (2010).

[10] www.boltcouncil.org/documents.html, Specification for structural joints using high-strength bolts, December 31, Version 2009, p. 16.2-72.

[11] S. Groeger and M. Gerlach: 3D-surface characterization for friction control, 1st CIRP Conference on Surface Integrity (CSI), Procedia Engineering 19, (2012) p.112.

[12] M. Gerlach, S. Groeger, and S. Schiefer, Funktionale 3D-Charaktersisierung für Dichtflächen an Zylindern, 17th ISC, Sept. 13.-14.2012 (Stuttgart, Germany), (2012) p.427.

[13] Geometrical product specifications (GPS) - Surface texture: Areal - Part 2: Terms, definitions and surface texture parameters (ISO 25178-2:2012).

(Received: October 30, 2014, Accepted: May 9, 2015) 